\title{
Hybrid procedure as an alternative to surgical palliation of high-risk infants with hypoplastic left heart syndrome and its variants
}

\author{
Prem S. Venugopal, MCh, FRCS, Karyn P. Luna, MD, David R. Anderson, FRCS, Conal B. Austin, FRCS, \\ Eric Rosenthal, FRCP, MRCPCH, Thomas Krasemann, MD, and Shakeel A. Qureshi, FRCP
}

\begin{abstract}
Objectives: Despite improvements in the surgical management of neonates with the hypoplastic left heart syndrome and its variants, there is a subset of children who have a high predicted mortality. We have analyzed and report our results with the hybrid approach in the management of these high-risk patients.
\end{abstract}

\begin{abstract}
Methods: Children identified by our selection criteria underwent the initial hybrid procedure performed in the catheterization laboratory. This consists of surgical banding of the branch pulmonary arteries and stenting of the arterial duct. This was followed 3 to 6 months later by the combined stage I and II Norwood operation or biventricular repair.

Results: Between December 2005 and May 2008, 21 neonates were selected for the hybrid procedure, of whom 16 had typical hypoplastic left heart syndrome. The remaining 5 neonates had severe aortic stenosis with borderline left ventricular dimensions or poor left ventricular function at presentation. Four neonates had a virtually intact interatrial septum and required urgent intervention immediately after birth. There were 6 deaths as inpatients or up to 30 days after the procedure and 1 interstage death before the combined stage I and II operation. Thus far, of 12 babies who have undergone the next operation, 9 have had the combined stage I and II operation and 3 have had a biventricular repair. Two of these 12 babies have died after the combined stage I and II operation.
\end{abstract}

Conclusion: A hybrid approach may be a valuable alternative to the management of high-risk neonates with hypoplastic left heart syndrome and its variants. (J Thorac Cardiovasc Surg 2010;139:1211-5)

Improvements have been made in the treatment of neonates and infants with the hypoplastic left heart syndrome (HLHS) and its variants. ${ }^{1,2}$ Although the overall survival is now greater than $70 \%$ after the initial Norwood stage I palliation, there is a subset of neonates in whom the mortality rate is high after this type of operation. ${ }^{3}$ Factors that increase the risk include birth weight less than $2.5 \mathrm{~kg}$, aortic atresia, intact or restrictive atrial septum, the presence of additional cardiac anomalies, prematurity, associated severe noncardiac genetic abnormality, and postnatal collapse with a $\mathrm{pH}$ less than $7 .{ }^{4-9}$ Prolonged cardiopulmonary bypass (CPB) and circulatory arrest are associated with a high mortality. ${ }^{10,11}$ Any treatment strategy that will reduce the need for prolonged $\mathrm{CPB}$ in the neonatal period could theoretically lead to an improvement in the results. ${ }^{412-14}$

In our unit, between 1995 and 2007, 211 patients with HLHS were treated surgically with the Norwood stage I operation. There was an overall mortality rate before stage II of $38 \%$ between 1995 and 2002 and 34\% after 2003. There

\footnotetext{
From the Evelina Children's Hospital, Department of Congenital Heart Disease, Guy's \& St Thomas' NHS Foundation Trust, London, United Kingdom.

Disclosures: None.

Received for publication March 24, 2009; revisions received Oct 12, 2009; accepted for publication Nov 14, 2009; available ahead of print Feb 1, 2010.

Address for reprints: Shakeel A. Qureshi, FRCP, Evelina Children's Hospital, Westminster Bridge Rd, London SE1 7EH, United Kingdom (E-mail: Shakeel.Qureshi@ gstt.nhs.uk).

$0022-5223 / \$ 36.00$

Copyright (C) 2010 by The American Association for Thoracic Surgery

doi:10.1016/j.jtcvs.2009.11.037
}

was a tendency toward a decrease in the 30-day mortality in the second era, but there was an increase in the interstage mortality. However, the mortality after stage II and stage III operations was low $(1.38 \%$ and $1.11 \%)$. One of the risk factors for a high mortality for the conventional Norwood staged operation was neonates with a birth weight of less than $2.5 \mathrm{~kg}(60 \%)$, and indeed there were no survivors when the birth weight was below $2.0 \mathrm{~kg}$. The hybrid approach to the management of neonates with HLHS has recently been used by Galantowicz and Cheatham, ${ }^{15}$ Bacha and associates, ${ }^{4}$ and Akintuerk and colleagues. ${ }^{12}$ The encouraging results from these authors influenced us to adopt the hybrid procedure in these neonates. The hybrid procedure involves a team effort between the surgeon and the interventional cardiologist working in the catheter laboratory and consists of banding of the branch pulmonary arteries, followed immediately by stenting of the arterial duct.

\section{METHODS AND PATIENTS}

Since December 2005, 21 neonates were considered for a hybrid procedure for the HLHS or its variants if their birth weight was less than $2.5 \mathrm{~kg}$, or irrespective of weight, if there was a possibility of a cerebral insult, intact or near intact interatrial septum, aortic stenosis with borderline or poorly contracting left ventricle, and other associated unusual anatomic variants. All the neonates were discussed at the institutional multidisciplinary meeting and a consensus was reached regarding the management strategy. Written parental consent was obtained before the procedure. The introduction of the procedure was approved under the "new treatment procedures protocol' ' of our institution. 


\author{
Abbreviations and Acronyms \\ $\mathrm{CPB}=$ cardiopulmonary bypass \\ HLHS $=$ hypoplastic left heart syndrome \\ $\mathrm{LV}=$ left ventricular \\ NEC $=$ necrotizing enterocolitis
}

HLHS or its variants were diagnosed antenatally in 16 of the 21 neonates, thus allowing a treatment strategy to be planned in advance of delivery and for extensive prenatal counseling with the parents. There were 5 patients with severe aortic stenosis with borderline left ventricular (LV) dimensions who were initially considered possibly not suitable for a biventricular repair, 1 of whom had also had postnatal collapse. In these 5 , additional balloon dilation of the aortic valve was carried out during the hybrid procedure through a sheath placed in the ascending aorta. The average weight at birth was $2.74 \mathrm{~kg}$ (range, $2.0-4.65 \mathrm{~kg}$ ).

\section{Hybrid Procedure}

All the procedures were performed in the catheter laboratory under general anesthesia. Median sternotomy was followed by bilateral branch pulmonary artery banding with a piece of polytetrafluoroethylene cut from a 3.5-mm tube graft and sutured in position over the branch pulmonary artery to an external diameter of $3 \mathrm{~mm}$. This was secured further in position with 5-0 Prolene polypropylene tacking suture (Ethicon, Inc, Somerville, $\mathrm{NJ})$ to the branch pulmonary arteries to prevent band migration. ${ }^{4}$ After this, a purse-string suture was placed between the pulmonary valve and the arterial duct. A $6 \mathrm{~F}$ short sheath was introduced through the purse-string suture with about $2 \mathrm{~mm}$ of the sheath extending into the lumen of the pulmonary artery. Angiography was performed in the lateral projection (and occasionally in the anteroposterior projection, if indicated), through the sidearm of the sheath in the main pulmonary artery to define the anatomy and measure the length and diameter of the arterial duct at several levels, namely, at the pulmonary arterial and aortic ends. A 0.018-inch floppy guide wire was maneuvered through the duct and placed in the descending aorta. Prostaglandin infusion was stopped and heparin (30-50 IU/kg body weight) was administered. A balloon-expandable premounted Genesis PSS stent (Cordis, Corp, Miami, Fla) of an appropriate diameter and length was chosen. This was usually 1 to $2 \mathrm{~mm}$ above the diameter of the duct and was delivered over the guide wire and deployed in the arterial duct, covering both the aortic and pulmonary ends. Correct position of the stent during the deployment of the stent was confirmed angiographically. At the end of the procedure, the sternum was closed in all the neonates, who were then transferred to the pediatric intensive care unit for further recovery.

Four of the neonates with an antenatally diagnosed additional intact or near intact atrial septum were delivered by cesarean section adjacent to the cardiac operating theater and were immediately transferred to the theater for open surgical septectomy. This was performed with CPB and circulatory arrest at $28^{\circ} \mathrm{C}$ with venous inflow occlusion but no cardioplegic arrest. On rewarming and weaning from $\mathrm{CPB}$, bands were placed on the branch pulmonary arteries after the oxygen saturation had stabilized. The neonate was transferred to the catheter laboratory for ductal stenting through the sternotomy incision. The average bypass time for this procedure was $44.6 \mathrm{~min}-$ utes and the average cardiac ischemic/circulatory arrest time was 5.6 minutes. Seven neonates with restrictive atrial septum underwent concomitant balloon atrial septostomy during or after the hybrid procedure with 1 requiring stenting of the atrial septum 2 days after the procedure.

All infants were closely followed up in the postoperative period until they were ready for the combined stage I and II operation. They were investigated by echocardiography and cardiac magnetic resonance imaging before the next operation. Cardiac catheterization was not performed routinely in these patients. The combined stage I and II palliation consisted of removal of the ductal stent, reconstruction of the ascending aorta and aortic arch with a homograft patch, Damus-Kay-Stansel type anastomosis, and a hemi-Fontan procedure. The latter involved a bidirectional cavopulmonary anastomosis in preparation for the completion of total cavopulmonary connection later with a baffle at the junction between the superior vena cava and the right atrium.

\section{RESULTS}

Patient characteristics and survival are as summarized in Table 1.

The anatomic subsets of the patients as diagnosed by echocardiography are summarized in Figure 1.

Five of the patients with true HLHS showed hemodynamically significant tricuspid regurgitation. One of these patients had severe rhythm disturbances, another had asphyxia requiring cardiopulmonary resuscitation in the immediate postnatal period, and 1 had aortopulmonary collaterals in addition to HLHS.

\section{Mortality}

There were 6 deaths after the hybrid procedure. One patient with aortic atresia had preoperative recurrent tachyarrhythmias and bradyarrhythmias and was acidotic when he underwent the procedure. Intraoperatively, further severe rhythm disturbances developed, as well as profound ventricular dysfunction after stent deployment. The possible reason could have been compromised coronary blood flow in view of the diminutive aorta and possible distortion of the ascending aorta by the stent before it was deployed fully. After repositioning of the stent, the native aorta and the coronary arteries were unobstructed on angiography, but a similar episode of arrhythmia occurred in the postoperative period and the patient died 19 hours after the procedure. A second patient was profoundly acidotic and showed evidence of systemic hypoperfusion before intervention, despite inotropic support. An emergency hybrid procedure was performed, but his condition continued to deteriorate after the procedure, necrotizing enterocolitis (NEC) developed, and he died 5 days after the intervention. The third patient was found to have pulmonary overcirculation after the hybrid procedure; repeat angiogram revealed multiple major aortopulmonary collateral arteries, which were coil closed. The infant's condition continued to deteriorate, and death occurred 48 hours after the procedure. The fourth patient had an intact atrial septum. She was delivered in the cardiac operating theater and had atrial septectomy and pulmonary artery banding. Because she was in unstable condition during and after the procedure, requiring inotropic support, the stenting of the patent ductus arteriosus was delayed by 36 hours. There was evidence of pulmonary overcirculation and she died 24 hours after the procedure. The fifth patient had moderate tricuspid valve regurgitation. After the hybrid procedure, the tricuspid regurgitation worsened with low cardiac output and the infant died 72 hours postoperatively. The sixth patient 
TABLE 1. Patient characteristics

\begin{tabular}{|c|c|c|c|c|c|c|c|c|c|}
\hline No. & Risk factor & $\begin{array}{c}\text { Birth } \\
\text { weight }(\mathbf{k g})\end{array}$ & Septectomy & Septostomy & $\begin{array}{c}\text { Time to } \\
\text { stage II (d) }\end{array}$ & Mortality & $\begin{array}{c}\text { Fetal } \\
\text { diagnosis }\end{array}$ & NEC & Anatomy \\
\hline 1 & Weight & 2.41 & No & Yes & 220 & No & Yes & No & MA/AA \\
\hline 2 & Intact septum & 3.5 & Yes & No & 190 & No & Yes & No & MA/AA \\
\hline 3 & Intact septum & 3.2 & Yes & No & 165 & No & Yes & No & $\mathrm{AA}$ \\
\hline 4 & CHARGE association & 2.6 & No & No & 285 & No & Yes & Yes & MS/AS \\
\hline 5 & Postnatal collapse & 2.58 & Yes & No & 180 & Yes & Yes & No & MS/AS \\
\hline 6 & ? Bivent repair & 3.8 & No & No & 392 & No & No & No & AS \\
\hline 7 & Weight & 2.4 & No & Yes & & Yes & Yes & Yes & MA/AA \\
\hline 8 & Associated cardiac anomaly & 2.8 & No & No & & Yes & No & No & MA/AA \\
\hline 9 & Weight & 2.2 & No & No & 145 & No & Yes & No & AA \\
\hline 10 & Weight & 2.1 & No & Yes & 89 & Yes & No & No & AA \\
\hline 11 & Weight; associated anomaly & 2.12 & No & No & 246 & No & Yes & No & AA \\
\hline 12 & ? Bivent repair & 3.2 & No & No & 321 & No & Yes & No & AS \\
\hline 13 & Restrictive septum/?bivent repair & 3.01 & No & Yes & 483 & No & Yes & Yes & AS \\
\hline 14 & Weight & 2.4 & No & Yes & & No & Yes & Yes & MA \\
\hline 15 & Postnatal collapse & 2.7 & No & No & & Yes & Yes & No & MA \\
\hline 16 & Intact septum & 3 & Yes & No & & Yes & Yes & No & AA \\
\hline 17 & ? Bivent repair & 2.6 & No & No & & Yes & Yes & No & MS/AS \\
\hline 18 & Weight & 2.2 & No & No & & Yes & Yes & No & MA/AA \\
\hline 19 & Weight & 2.2 & No & No & & No & Yes & No & AA \\
\hline 20 & ? Bivent repair & 4.65 & No & Yes & 195 & No & Yes & Yes & AS \\
\hline 21 & Weight & 2.0 & No & No & & No & Yes & No & AA \\
\hline
\end{tabular}

$A A$, aortic atresia; $A S$, aortic stenosis; ? Bivent, possible biventricular repair, CHARGE, Coloboma of the eye, Heart defects, Atresia of the choanae, Retardation of growth and/or development, Genital and/or urinary abnormalities, and Ear abnormalities and deafness; $M A$, mitral atresia, $M S$, mitral stenosis; $N E C$, necrotizing enterocolitis; TR, tricuspid regurgitation.

with borderline LV dimension died unexpectedly on the fourth postoperative day of suspected aspiration.

None of the patients with preoperative echocardiographically significant tricuspid regurgitation survived (Table 2).

\section{Other Complications}

Three patients had NEC, and 2 other neonates had suspicion of but not definite NEC ( 2 patients were Bell ${ }^{16}$ stage II and 3 were Bell stage I). Thus, there was a $23.8 \%$ incidence of possible or definite NEC. One patient died, as mentioned earlier, another patient required bowel resection after ileal perforation, and the remaining 3 patients were treated conservatively and all recovered.

One patient undergoing ballooning of the aortic valve had cerebral hemorrhage 4 months after the procedure. He recovered completely from this.

\section{Outcome}

There was 1 interstage death of unknown cause at the local hospital. Five patients required further interstage intervention. Three of the 5 required an additional stent either to cover previously uncovered ductal tissue or to overlap a partially migrated previous stent. One patient with aortic stenosis and borderline LV dimensions underwent repeat balloon aortic valvotomy. One patient required mitral valve repair before biventricular repair (Ross procedure).

Of the 14 survivors of the hybrid procedure, 9 underwent combined stage I and II operation and a further 3 underwent a successful biventricular repair. The average time from the hybrid to the next operative procedure was 242.6 days (range, 89-483 days). The average CPB time for combined stage I and II was 204.6 minutes (range, 134-436 minutes), the average cumulative cardiac ischemic time was 119.9 minutes (range, 56-270 minutes), and the average cumulative circulatory arrest time was 67.1 minutes (range, 20-137 minutes). The average CPB time for the biventricular repair was 178 minutes and the cardiac ischemic time was 142 minutes.

There were 2 deaths among 9 patients after combined stage I and II procedure. One of these died of thrombosis of the innominate vein and the branch pulmonary arteries because of hypoplasia of theses branches resulting in raised pulmonary vascular resistance and inadequate forward blood flow. The second patient did not tolerate the stage I and II repair; the Glenn anastomosis was taken down and a modified Blalock-Taussig shunt created. He continued to have severe tricuspid regurgitation and died of low output failure.

Two infants are being followed up and are awaiting stage II palliation.

\section{Biventricular Repair}

Five patients with severe aortic stenosis with borderline LV dimensions underwent the hybrid procedure combined with aortic balloon valvuloplasty. Of these, 1 neonate died of suspected aspiration 4 days after the hybrid procedure. 


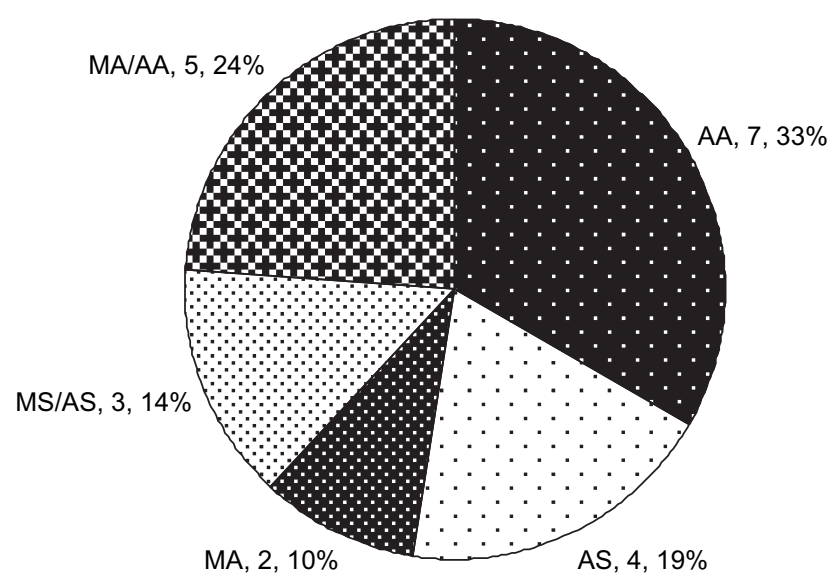

FIGURE 1. Anatomic subtypes. $M A$, Mitral atresia; $A A$, aortic atresia; $M S$, mitral stenosis; $A S$, aortic stenosis.

Three patients underwent successful biventricular repair. One of the 5 patients underwent the combined stage I and II Norwood procedure because of persistently small LV dimensions.

\section{DISCUSSION}

The initial concept of banding the branch pulmonary arteries and stenting the arterial duct in infants with HLHS was reported by Gibbs and associates. ${ }^{14}$ This was aimed as a bridge to cardiac transplantation. Subsequently, Akintuerk and coworkers ${ }^{12}$ modified the technique, but in both the 2 parts of the procedure were performed separately, the pulmonary artery banding in the theater and the stenting of the arterial duct in the catheter laboratory. Galantowicz and Cheatham ${ }^{15}$ and Bacha and associates ${ }^{4}$ modified this to a true hybrid procedure, in which both the banding and stenting are performed during the same procedure in the catheter laboratory. We have used the approach developed by Galantowicz and Cheatham. ${ }^{15}$

Stage I Norwood palliation for HLHS is now accepted as a standard treatment. The overall survival is in excess of $70 \%$. However, there is a subgroup of high-risk HLHS and its variants which present a challenging clinical problem. Norwood type surgical approaches for these patients have carried a high mortality rate. ${ }^{17}$ This is independent of the size of the center and the number of patients treated. ${ }^{1,3,7}$ Children with low birth weight and asphyxia before surgery do not tolerate CPB and total circulatory arrest; thus, these are additional factors for high mortality. The hybrid strategy of banding of bilateral pulmonary artery branches and ductal stenting offers a possible solution, in which the cerebral and coronary perfusion is maintained and the pulmonary vasculature is protected from systemic pressure. ${ }^{8}$ This potentially gains vital time to stabilize the patients, correct other noncardiac anomalies, and delay the Norwood operation.

In our series, the mortality after the hybrid procedure has been lower than after the surgical approach in these high-
TABLE 2. Patients having hybrid operations $(n=21)$

\begin{tabular}{lcc}
\hline & Stage I survivors & Stage II survivors \\
\hline Low birth weight $(\mathrm{n}=9)$ & $6 / 9$ & $3 / 4$ \\
Intact/restrictive septum $(\mathrm{n}=4)$ & $3 / 4$ & $2 / 3$ \\
Asphyxia $(\mathrm{n}=3)$ & $1 / 3$ & $1 / 1$ \\
Boderline LV dimension $(\mathrm{n}=5)$ & $4 / 5$ & $4 / 4$. \\
Total: 21 & $14 / 21^{*}$ & $10 / 12$ \\
\hline
\end{tabular}

$L V$, Left ventricular. *Includes 1 interstage death.

risk patients. In infants with low birth weight, survival after the hybrid procedure was $66 \%$ (6/9).Those infants with an intact or near intact interatrial septum are another high-risk group. Seventy-five percent (3/4) of this subgroup in our series survived. Only 1 of the 3 infants who had had postnatal collapse survived. A further point of interest relates to infants with pre-existing hemodynamically significant tricuspid regurgitation, none of whom survived. It is worth mentioning that 3 of these also had other additional risk factors.

Our relatively small series is different from reports already published in the literature in that we focused on high-risk infants. ${ }^{4,12}$ The combined stage I and II operation carries a higher mortality risk than in the "standard" Norwood procedure. The number of patients in this subgroup is small so that it is difficult to identify any risk factors.

NEC has occurred in a significant number $(23.8 \%)$ of infants. This compares with an incidence of approximately $18 \%$ in all children undergoing the Norwood I palliation. ${ }^{18}$ Although diastolic runoff may contribute to the development of NEC, further studies are required to identify the risk factors. ${ }^{19}$

The combined stage I and II operation after the initial hybrid procedure is a major undertaking. The operation is longer and more complex. CPB may be prolonged, although with increasing experience these times have been reduced. ${ }^{20}$ In some infants a significant narrowing of the aorta proximal to the isthmus may develop. This may be due to variation in flow after the stent or to progression of ductal constriction. This may have relevance to the timing of combined stage I and II operation because of the possible compromised cerebral and coronary perfusion. ${ }^{8,20}$

The hybrid approach allows for an alternative strategy for the treatment of infants with aortic stenosis, with poor LV function or borderline LV dimensions. ${ }^{13}$ Three of 4 surviving infants with aortic stenosis underwent a successful biventricular repair, whereas 1 infant, because of lack of left ventricular growth, underwent a combined stage I and II operation.

\section{CONCLUSION}

The hybrid approach is a satisfactory alternative in the management of high-risk infants with HLHS and its variants. Although our results are encouraging, further studies are required to identify risk factors. An important advantage 
of this approach is in infants with aortic stenosis and borderline LV dimensions in whom the left ventricle is given time to grow enough to allow biventricular repair.

\section{References}

1. Ashburn DA, McCrindle BW, Tchervenkov CI, Jacobs ML, Lofland GK, Bove EL, et al. Outcomes after the Norwood operation in neonates with critical aortic stenosis or aortic valve atresia. J Thorac Cardiovasc Surg. 2003;125:1070-82.

2. Sano S, Ishino K, Kado H, Shiokawa Y, Sakamoto K, Yokota M, et al. Outcome of right ventricle-to-pulmonary artery shunt in first-stage palliation of hypoplastic left heart syndrome: a multi-institutional study. Ann Thorac Surg. 2004;78: 1951-8.

3. Stasik CN, Gelehrter S, Goldberg CS, Bove EL, Devaney EJ, Ohye RG. Current outcomes and risk factors for the Norwood procedure. J Thorac Cardiovasc Surg. 2006;131:412-7.

4. Bacha EA, Daves S, Hardin J, Abdulla RI, Anderson J, Kahana M, et al. Singleventricle palliation for high-risk neonates: the emergence of an alternative hybrid stage I strategy. J Thorac Cardiovasc Surg. 2006;131:163-71.

5. Forbess JM, Cook N, Roth SJ, Serraf A, Mayer JE Jr, Jonas RA. Ten-year institutional experience with palliative surgery for hypoplastic left heart syndrome. Risk factors related to stage I mortality. Circulation. 1995;92(9 Suppl):II262-6.

6. Gaynor JW, Mahle WT, Cohen MI, Ittenbach RF, De Campli WM, Steven JM, et al. Risk factors for mortality after Norwood procedure. Eur J Cardiothoracic Surg. 2002;22:82-9.

7. Krasemann T, Fenge H, Kehl HG, Rukosujew A, Schmid C, Scheld HH, et al. A decade of staged Norwood palliation in hypoplastic left heart syndrome in a midsized cardiosurgical center. Pediatr Cardiol. 2005;26:751-5.

8. Akintürk H, Michel-Behnke I, Valeske K, Mueller M, Thul J, Bauer J, et al. Hybrid transcatheter-surgical palliation: basis for univentricular or biventricular repair-the Giessen experience. Pediatr Cardiol. 2007;28:79-87.

9. Tweddell JS, Hoffman GM, Mussatto KA, Fedderly RT, Berger S, Jaquiss RD, et al. Improved survival of patients undergoing palliation of hypoplastic left heart syndrome: lessons learned from 115 consecutive patients. Circulation. 2002; 106(12 Suppl. 1):I82-9
10. Kern JH, Hayes CJ, Michler RE, Gersony WM, Quaegebeur JM. Survival and risk factor analysis for the Norwood procedure for hypoplastic left heart syndrome. Am J Cardiol. 1997;80:170-4.

11. Malec E, Januszewska K, Kolcz J, Pajak J. Factors influencing early outcome of Norwood procedure for hypoplastic left heart syndrome. Eur J Cardiothoracic Surg. 2000;18:202-6.

12. Akintuerk H, Michel-Behnke I, Valeske K, Mueller M, Thul J, Bauer J, et al Stenting of the arterial duct and banding of the pulmonary arteries: basis for combined Norwood stage I and II repair in hypoplastic left heart. Circulation. 2002; 105:1099-103.

13. Michel-Behnke I, Akintuerk H, Marquardt I, Mueller M, Thul J, Bauer J, et al Stenting of the ductus arteriosus and banding of the pulmonary arteries: basis for various surgical strategies in newborns with multiple left heart obstructive lesions. Heart. 2003;89:645-50

14. Gibbs JL, Wren C, Watterson KG, Hunter S, Hamilton JR. Stenting of the arteria duct combined with banding of the pulmonary arteries and atrial septectomy or septostomy: a new approach to palliation for the hypoplastic left heart syndrome Br Heart J. 1993;69:551-5.

15. Galantowicz M, Cheatham JP. Lessons learned from the development of a new hybrid strategy for the management of hypoplastic left heart syndrome. Pediatr Cardiol. 2005;26:190-9.

16. Bell MJ, Ternberg JL, Feigin RD, Keating JP, Marshall R, Barton L, et al. Neonatal necrotizing enterocolitis: therapeutic decisions based upon clinical staging. Ann Surg. 1978;187:1-13.

17. Pizarro C, Davis DA, Galantowicz ME, Munro H, Gidding SS, Norwood WI. Stage I palliation for hypoplastic left heart syndrome in low birth weight neonates: can we justify it? Eur J Cardiothorac Surg. 2002;21:716-20.

18. Jeffries HE, Wells WJ, Starnes VA, Wetzel RC, Moromisato DY. Gastrointestina morbidity after Norwood palliation for hypoplastic left heart syndrome. Ann Thorac Surg. 2006;81:982-7.

19. McElhinney DB, Hedrick HL, Bush DM, Pereira GR, Stafford PW, Gaynor JW et al. Necrotising enterocolitis in neonates with congenital heart disease: risk factors and outcomes. Pediatrics. 2000;106:1080-7.

20. Galantowicz M, Cheatham JP, Phillips A, Cua CL, Hoffman TM, Hill SL, et al. Hybrid approach for hypoplastic left heart syndrome: intermediate results after the learning curve. Ann Thorac Surg. 2008;85:2063-70. 